\title{
Kradljivci vremena u sestrinskoj praksi Time thieves in nursing practice
}

\author{
Slađana Režić, Ana Savović2, Kristina Pauker ${ }^{3}$ \\ 'Klinički bolnički centar Zagreb, Odjel za osiguranje i unapređenje kvalitete zdravstvene zaštite, Kišpatićeva 12, 10000 Zagreb, Hrvatska \\ 'University Hospital Center Zagreb, Department of quality assurance and advancement of health care, Kišpatićeva 12, 10000 Zagreb, Croatia \\ ${ }^{2}$ Klinički bolnički centar Zagreb, Klinika za torakalnu kirurgiju Jordanovac, Jordanovac 104, 10000 Zagreb, Hrvatska \\ ${ }^{2}$ University Hospital Center Zagreb, Clinic for thoracic surgery Jordanovac, Jordanovac 104, 10000 Zagreb, Croatia \\ ${ }^{3}$ Klinički bolnički centar Zagreb, Klinika za plućne bolesti Jordanovac, Zavod za respiracijsku insuficijenciju i bolesti plućne cirkulacije, Intenzivna skrb, \\ Jordanovac 104, 10000 Zagreb, Hrvatska \\ ${ }^{3}$ University Hospital Center Zagreb, Clinic for respiratory disease Jordanovac, Department of respiratory insufficiency and the disease of pulmonary \\ circulation, intensive care unit, Jordanovac 104, 10000 Zagreb, Croatia
}

\section{Sažetak}

Svrha učinkovitosti upravljanja vremenom osigurava dostatni obim vremena za svrhe izvršavanja aktivnih radnih zadataka te za provođenje osobnih interesa i obveza. Upravljanje vremenom znači najučinkovitije korištenje vremena u svrhu provođenja aktivnih radnih zadataka. Danas postoje znanstveno verificirane metode koje poboljšavaju stupanj organizacije i učinkovitosti obaveznog radnog vremena. Čimbenici koji se definiraju kao „,kradljivci vremena“ neučinkovite su aktivnosti, neželjeni prekidi i događaji koji uzrokuju „krađu“ vremena. Opisujemo najučestalije kradljivce vremena koji su zabilježeni u sestrinskoj praksi na odjelima dviju klinika. Upotrebljen je upitnik „Samoprocjena - moji kradljivci vremena“. U istraživanje su uključene 62 medicinske sestre. Anketu „Samoprocjena - moji kradljivci vremena“ ispunila su 62 ispitanika. Nema statistički značajne razlika u samoprocjeni postojanja kradljivaca vremena u odnosu na mjesto rada ispitanika, te na demografsko-sociološke čimbenike ispitanika.

Ključne riječi: upravljanje vremenom • kradljivci vremena • sestrinstvo Kratki naslov: Kradljivci vremena

\begin{abstract}
The purpose of the effectiveness of time management ensures sufficient scope of time for the purpose of serving active work tasks and to conduct personal interests and obligations. Time management means the most effective use of time for the implementation of active tasks. Today there are scientifically verified methods that improve the level of organization and effectiveness of mandatory working hours. Factors that are defined as "time thieves" are ineffective activities, unwanted interruptions and events that cause "theft" of time. We describe the most common time stealers that have been reported in nursing practice in the department's two clinics. Used the questionnaire "Self assessment - my thieves of time". The study included 62 nurses. The survey "Self assessment - my thieves of time" was filled by the 62 respondents. We didn't find a statistically significant difference in self-reported time thieves in relation to the workplace of the respondents, as well as demographic and sociological factors of the subjects.
\end{abstract}

Keywords: time management $•$ thieves of time $\cdot$ nursing

Running head: Thieves of time

Received December $5^{\text {th }} 2016$;

Accepted December $11^{\text {th }}$ 2016;

Autor za korespondenciju/Corresponding author: Slađana Režić, mag. med. techn., University Hospital Center Zagreb, Department of quality assurance and advancement of health care, Kišpatićeva 12, 10000 Zagreb, Croatia•GSM: +38591793 7475•E-mail:sladjana.rezic@gmail.com

\section{Uvod/Introduction}

Osnovni cilj upravljanja vremenom učinkovito je korištenje vremena za obavljanje radnih aktivnosti opisanih u pravilnicima o izvršavanju radnih zadataka [1]. Značajan broj autora iznalazi da čovjek ne može upravljati vremenom, ali da može utjecati na način korištenja vremena. Učinkovito korištenje osobnog vremena omogućuje viši stupanj kontrole osobnih aktivnosti i učinkovitije iznalaženje prioriteta, osigurava se veći obim tzv. "slobodnog vremena“ za obitelj, te se posljedično smanjuje stupanj stresa. Prema Parkinsovoj teoriji vremenskog menadžmenta proizlazi da što više vremena imamo za izvršavanje određenog zadatka to je potrebito utrošiti veći obim istoga [2].
Upravljanje vremenom ovisi o subjektivnom shvaćanju vremena, te postoje metode koje pomažu u upravljanju i planiranju vremena. Najčešće se upotrebljavaju planeri vremena. Uporabom planera određuju se aktivnosti na dnevnoj, mjesečnoj i godišnjoj razini. U tijeku planiranja aktivnosti, potrebno je provoditi evaluaciju provedenog. Simultano planiranje i kontrola ishoda poboljšava stupanj učinkovitosti u izvršenju planiranih aktivnosti.

Osim metode „planera vremena“, danas su u uporabi Alpen-metoda te $A B C$-analiza [3]. 
Alpen-metoda podučava da u planirano vrijeme uvijek uključujemo društvene i neočekivane aktivnosti. Alpen preporučuje da planiramo oko $50 \%$ osobnog dnevnog vremena, te $25 \%$ vremena za provođenje društvenih aktivnosti, a $25 \%$ za neočekivane aktivnosti. Uporaba navedenih preporuka omogućuje pojedincu povećanu učinkovitost i veći stupanj zadovoljstva uz istovremeni manji obim stresa. ABC-analiza podučava o A, B, C zadacima pri čemu su A zadaci najvažniji, te iste moramo obavljati isključivo samostalno. Takvih zadataka dnevno može biti jedan do dva. B zadaci su važni, ali iste mogu obavljati i druge osobe. Dnevno ih je moguće završiti od dva do tri.

C zadaci rutinski su zadaci koji često oduzimaju najviše vremena, a imaju najmanju važnost. Ovaj tip zadataka mogu obavljati druge, ali bliske nam osobe.

Davanje zadataka za izvršenje drugim osobama omogućuje nam dobivanje više vremena za izvršavanje najvažnijih zadataka, tj. A zadataka. Mnogi nisu navikli na opisani sustav raspodjele izvršavanja radnih zadataka ili pak prevladava subjektivni osjećaj da druge osobe neće uspješno obaviti zadatak. Potrebno je napomenuti da rezultati recentnih studija iznalaze kako je uspješan menadžer svog vremena istovremeno i uspješan u raspodjeli radnih zadataka. Nadalje, Srića opisuje preporuke kako upravljati osobnim vremenom, procijeniti osobne mogućnosti, učinkovito preuzimati obaveze, odabrati prioritete u rješavanju obaveza te znati reći ne [4].

Jones opisuje praktične preporuke koje služe kao pomoć u upravljanju vremenom [npr. dođite malo ranije na posao i isplanirajte svoj dan; napišite popis zadataka koje trebate obaviti; odredite prioritete; odredite vrijeme za svaku aktivnost; budite svjesni da različiti zadaci traže različito vrijeme izvedbe; ostavite uvijek vremena za neplanirane aktivnosti; naučite reći ne [2]. Prema rezultatima publiciranog istraživanja, Elsabahy zaključuje da postoji značajna statistička povezanost $u$ treningu upravljanja vremenom i zadovoljstva poslom glavnih sestara. Rezultati preporučuju provođenje metoda trajne edukacije glavnih medicinskih sestara/tehničara u svrhu poboljšanja upravljanje vremenom [5].

Do danas znanstveno verificirani "kradljivci vremena" su, i to: telefonski kradljivci, kradljivci na sastancima te komunikacijski kradljivci [6]. U tijeku 2009. godine Kalauz i Kurtović navode najčešće kradljivce vremena u sestrinskoj praksi: problemi u organizaciji, delegiranje zadataka, posjete te sastanci [7]. Cilj je rada utvrditi koji su najčešći „kradljivci vremena" u sestrinskoj praksi, i to na dvije klinike Kliničkog bolničkog centra Zagreb, te postoji li razlika u rezultatima u odnosu na granu odjela, starosnu dob ispitanika, godine radnog staža te stupnja obrazovanja.

\section{Metode i ispitanici/Methods and participants}

Korišten je upitnik "Samoprocjena - moji kradljivci vremena" [original autora L. J. Selwerta]. U istraživanju su uključene medicinske sestre Klinike za torakalnu kirurgiju te Klinike za plućne bolesti Jordanovac Kliničkog bolničkog centra Zagreb. U istraživanje su uključene 62 medicinske sestre. Anketu "Samoprocjena - moji kradljivci vremena" ispunila su 62 ispitanika.

\section{Rezultati/Results}

Uključne kriterije zadovoljila su 62 ispitanika [5 ispitanika muškog spola (8\%), 57 ispitanika ženskog spol (92\%)]. U odnosu na stupanj obrazovanja, 1 ispitanica je diplomirana medicinska sestra (2\%), 19 ispitanika prvostupnici su sestrinstva (31\%), a 41 ispitanik ima srednju stručnu spremu (67\%). Slika [1]

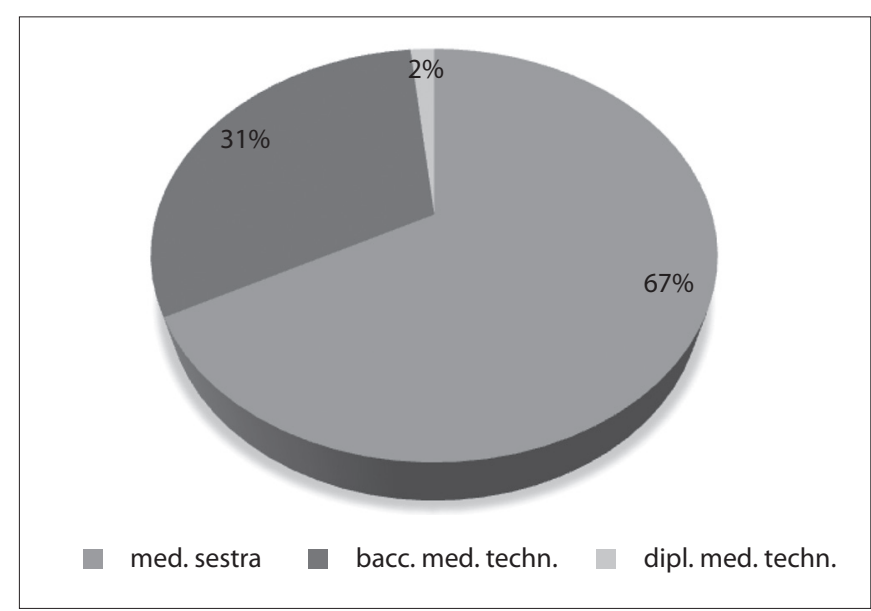

SLIKA [1] Raspodjela ispitanika prema stupnju edukacije.

U odnosu na obim radnog staža, 10 ispitanika ima manje od 5 godina (16\%), 8 ispitanika između 5-10 godina radnog staža (13\%), 31 ispitanik ima između 10-20 godina (51\%), te 12 ispitanika je ima više od 20 godina radnog staža (20\%). Slika [2]

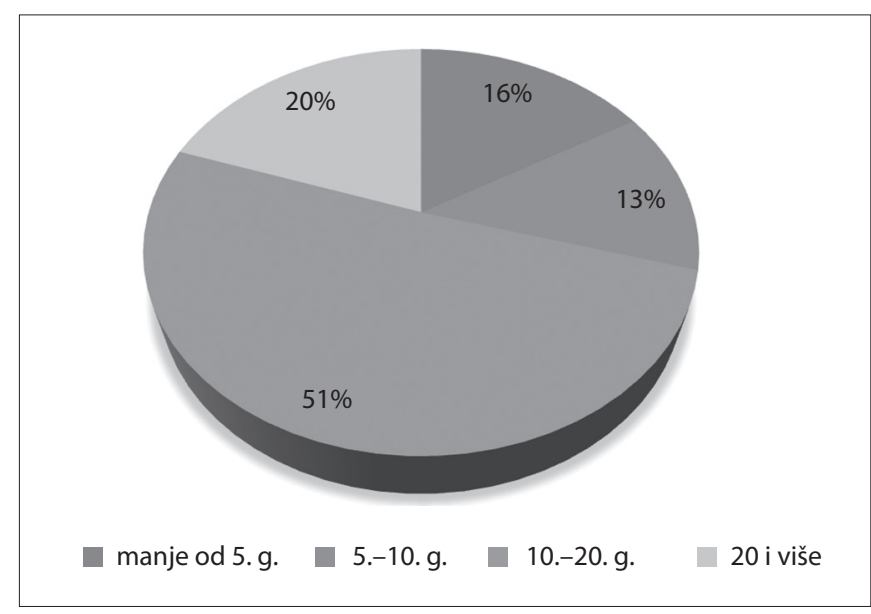

SLIKA [2] Raspodjela ispitanika prema obimu radnog staža.

U odnosu na mjesto zaposlenja [klinika], 15 ispitanika radi na kirurškom odjelu (24\%), 17 ispitanika u torakokiruškoj intenzivnoj jedinici (28\%), 20 ispitanika u pulmološkoj intenzivnoj jedinici (33\%), a 9 ispitanika u torakokirurškoj operacijskoj sali (15\%). [Slika 3] 


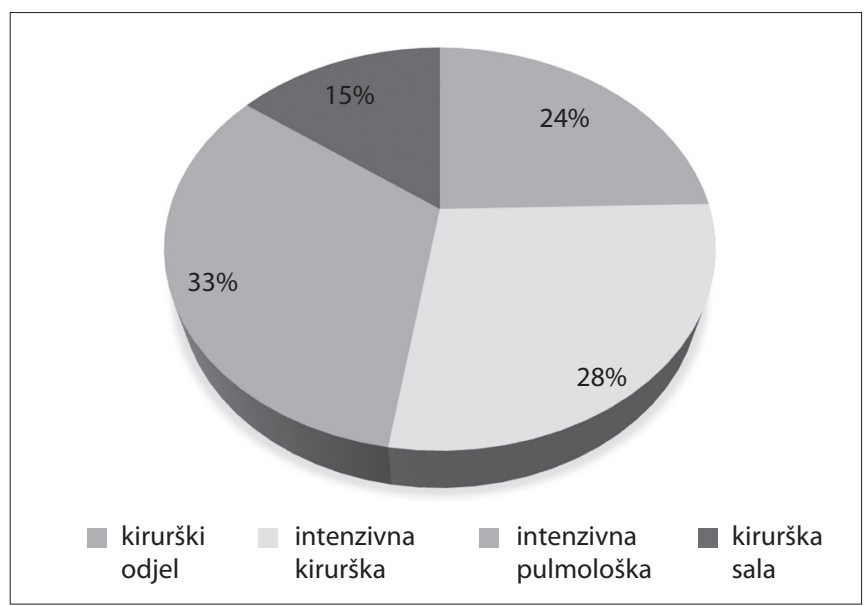

SLIKA [3] Raspodjela ispitanika u odnosu na mjesto rada [klinički odjeli].

Ispitanici su najmanje ocjene dodjeljivali 10. pitanju. Pitanje se odnosi na tvrdnju: „teško mi je reći ne kada drugi nešto žele od mene i kada bih zapravo mogla obavljati svoje vlastite poslove", te se može reći da ispitanici najvećim krad- ljivcem vremena smatraju nemogućnost „reći ne“. Među najvećim kradljivcima vremena, prema dobivenim ocjenama, jesu : telefon („telefon me stalno ometa, razgovori su većinom nepotrebno dugi“), sastanci ("sastanci često traju predugo, a njihovi su rezultati za mene rijetko zadovoljavajući ${ }^{\prime \prime}$ ), prioriteti („često mi nedostaju jasni prioriteti i pokušavam istovremeno obaviti velik broj zadataka, previše se bavim sitnicama, a premalo se mogu koncentrirati na najvažnije zadatke"). [Slika 4].

Rezultati prosječene ocjene po pitanju s obzirom na stupanj edukacije iznalaze da ne postoje značajne razlike $u$ odgovorima između prvostupnica sestrinstva i medicinskih sestara srednje stručne spreme. [Slika 5].

Rezultati prosječne ocjene u odnosu na duljinu radnog staža pokazuju da ispitanice s manjim stažem daju više prosječne ocjene, nego osobe s dužim stažem. [Slika 6].

U svrhu verifikacije statističke značajnosti razlika s obzirom na odjel [mjesto zaposlenja] ispitanika, uporabili smo analizu varijance, ANOVA. Rezultati pokazuju da ne postoji statistički značajna razlika u srednjim ocjenama među grupama obzirom na odjel. [Tablica 1].

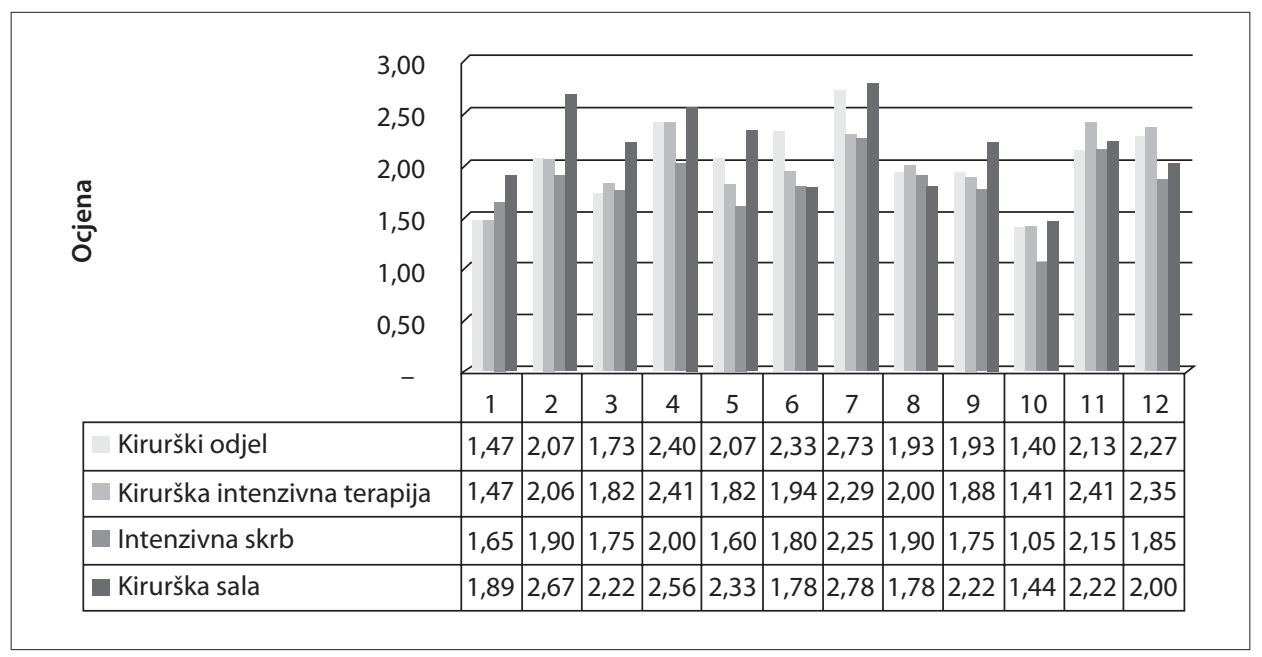

SLIKA [4] Prosječne ocjene razvrstane u odnosu na pojedinačno pitanje s obzirom na klinički odjel.

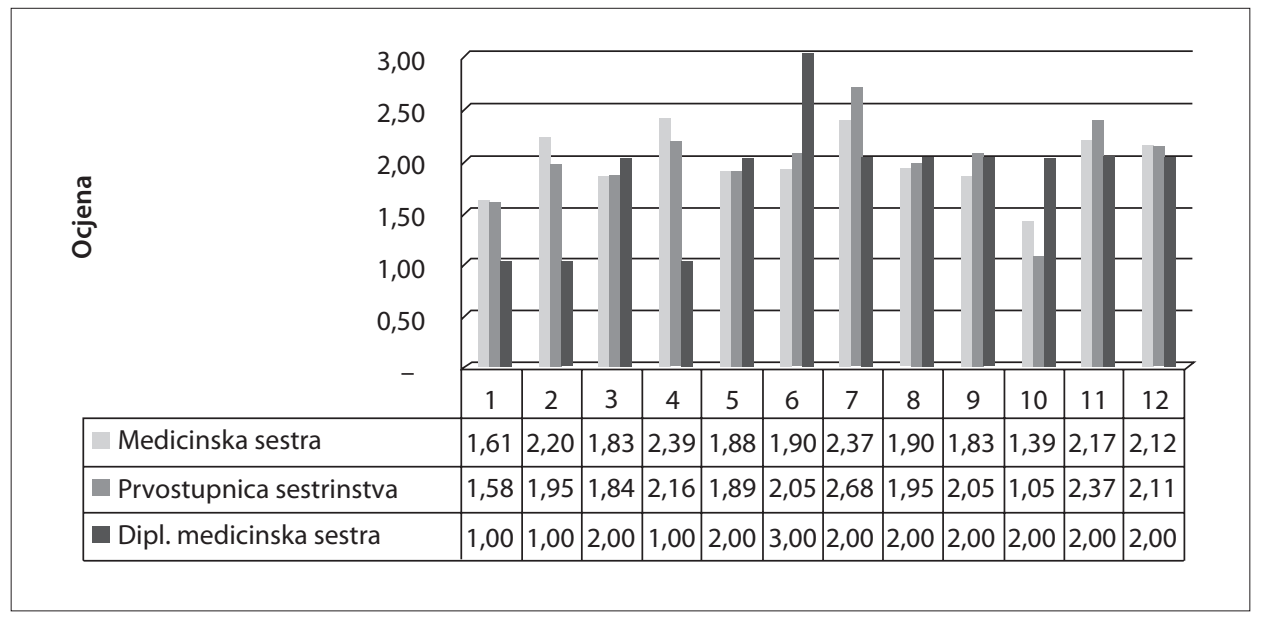

SLIKA [5] Prosječne ocjene razvrstane u odnosu na pojedinačno pitanje s obzirom na stručnu spremu. 


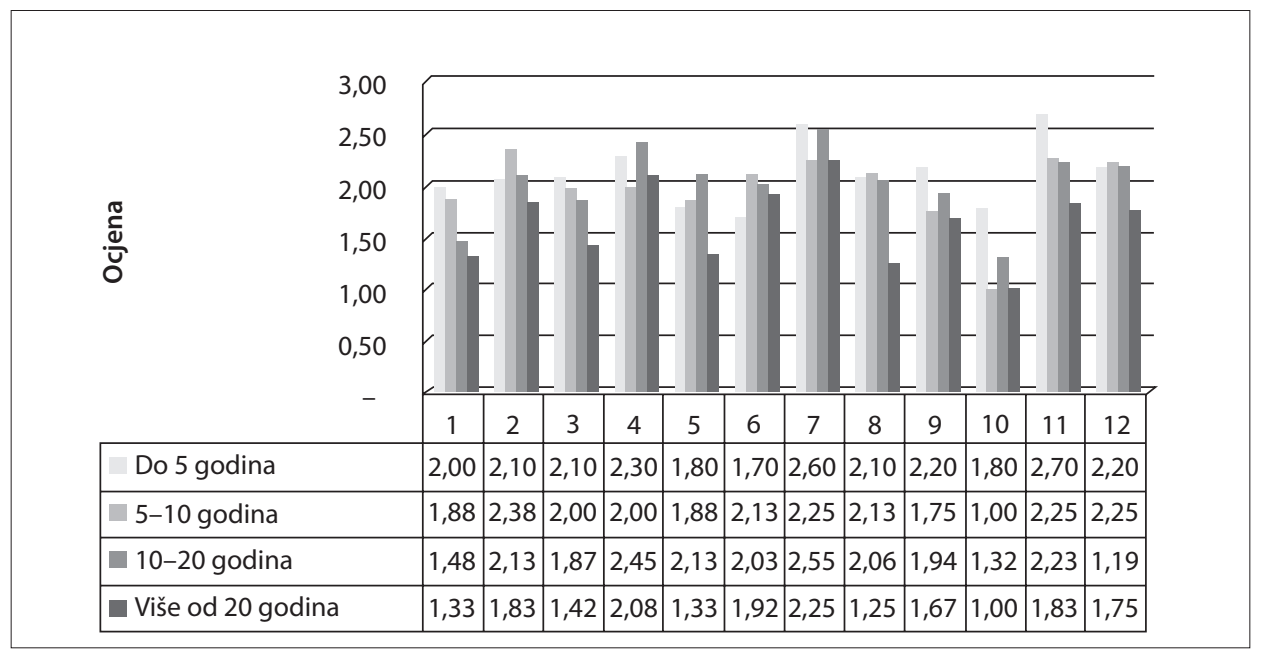

SLIKA [6] Prosječne ocjene razvrstane u odnosu na pojedinačno pitanje s obzirom na duljinu radnog staža.

Ne postoji statistički značajna razlika u srednjim ocjenama među grupama obzirom na stupanj edukacije [Tablica 2].
Ne postoji statistički značajna razlika u srednjim ocjenama među grupama obzirom na duljinu radnog staža [Tablica 3].

TABLICA [1] povezanost mjesta zaposlenja i prosječnih vrijednosti grupa

\begin{tabular}{lcccccc}
\hline ANOVA & $\begin{array}{c}\text { Df(stupnjevi } \\
\text { slobode) }\end{array}$ & $\begin{array}{c}\text { Suma kvadrata } \\
\text { odstupanja }\end{array}$ & $\begin{array}{c}\text { Srednje kvadratno } \\
\text { odstupanje }\end{array}$ & F-vrijednost & p-vrijednost \\
\hline između uzoraka & 3 & 0,9415 & 0,31385 & \multirow{2}{*}{1,4305} & \multirow{2}{*}{0,2433} \\
\hline unutar uzoraka & 57 & 12,5053 & 0,21939 & & \\
\hline
\end{tabular}

TABLICA [2] utjecaj stupnja obrazovanja spreme na prosječne ocjene grupa

\begin{tabular}{cccc}
\hline \multirow{2}{*}{ test } & $\mathbf{t}$ & Df & p-vrijednost \\
\cline { 2 - 4 } & -0.0781 & 49.714 & 0.938 \\
\hline
\end{tabular}

TABLICA [3] povezanost duljine radnog staža na prosječne ocjene grupe

\begin{tabular}{llllll}
\hline ANOVA & $\begin{array}{l}\text { Df (stupnjevi } \\
\text { slobode) }\end{array}$ & $\begin{array}{l}\text { Suma kvadrata } \\
\text { odstupanja }\end{array}$ & $\begin{array}{l}\text { Srednje kvadratno } \\
\text { odstupanje }\end{array}$ & F-vrijednost & p-vrijednost \\
\hline između uzoraka & 3 & 0,6984 & 0,23281 & 1,0409 & 0,3815 \\
\hline unutar uzoraka & 57 & 12,7485 & 0,22366 & \\
\hline
\end{tabular}

\section{Rasprava/Discussion}

Kradljivci vremena prisutni su u provođenju aktivnih radnih zadataka. Oni smanjuju stupanj produktivnosti i stupanj zadovoljstva poslom. Stoga je vidljiva potreba uporabe metoda za učinkovito upravljanje osobnim vremenom. Cilj je članka utvrditi koji su najveći kradljivci vremena te postoji li statistička razlika među ispitanicima u dvije kliničke ustanove KBC-a Zagreb. Rezultati pokazuju da ne postoje statističke razlike s obzirom na dob, stručnu spremu ili staž, ali kako se radi o malom uzorku postoji u budućnosti potreba za provođenjem sličnog istraživanja uz uključenje značajno većeg broja ispitanika. Potrebno je napomenuti: upravljanje vremenom umijeće je koje se može naučiti. Važno je osvijestiti da kradljivci vremena postoje, ali i da postoje načini kojima njima možemo upravljati. Na taj način više ćemo cijeniti i svoje i tuđe vrijeme.

\section{Authors declare no conflict of interest}




\section{Literatura/References}

[1] Pološki Vokić N, Mrđenović R. Razlike u upravljanju vremenom hrvatskih menadžera s obzirom na spol i hijerarhijsku razinu. UDK. 2007.

[2] Lothar SJ. Vremenski menadžment-organizirajte svoje vrijeme. Zagreb. Naklada Slap.1999.

[3] Obžetić M. Upravljanje vremenom u sestrinskoj praksi. Završni rad. Sveučilište Sjever.

[4] Srića V. Izazov - prioriteti i vrijeme.(12.09.2016.) Avalaible at: www-velimirsrica.com. Accessed December $5^{\text {th }} 2016$
[5] Elsabahy HE, Sleem WF, Atroush HG. Effect of time management program on job satisfaction fot head nurses. Journal of education and practice. 2015.

[6] Kurtović B, Grgas-Bile C. Kradljivci vremena u svakodnevnom radu medicinskih sestara. Shock. 2013: 101-7.

[7] Kalauz S, Kurtović B. Upravljanje vremenom u sestrinskoj praksi. Zbornik radova 9 simpozija Zdravstvenog veleučilišta u Zagrebu. Opatija, 14-16.5.2009. 